\title{
TUBERCULOSIS AND PERIODONTAL DISEASE, WITH SPECIAL REFERENCE TO THE COLLAGEN FIBERS
}

\author{
SIGURD RAMFJORD, L.D.S., M.S., PH.D. \\ From the University of MIichigan School of Deniistry, Department of Oral Pathology \\ and Periodontia, Ann Arbor, Mich.
}

\begin{abstract}
A NUMBER of chronic debilitating diseases, including tuberculosis, have been considered predisposing or contributing factors in the development of periodontal disease. ${ }^{2,6}, 10,31$ Some authors ${ }^{28,33,37}$ have even claimed that the periodontal lesions associated with these systemic diseases are characteristic enough to be helpful in arriving at a diagnosis of the systemic disease. A mild, painless, specific type of gingivitis associated with pulmonary tuberculosis was described by Cahn, ${ }^{8}$ who also reported "roentgenographic evidence of enlarged, swollen intertrabecular spaces between and around the teeth." Cipes ${ }^{9}$ examined more than one thousand tuberculous patients and found a high incidence of characteristic gingivitis which varied in severity and extent proportionately to the pulmonary involvement. A definite association between pulmonary tuberculosis and periodontal lesions was also reported by Kramer ${ }^{21}$ and Brody. ${ }^{5}$ They also reported periodontal bone changes, and were later supported by Goadby, ${ }^{14}$ who attributed these bone changes in the jaw to a loss of lime salts and a subsequent formation of granulation tissue. A general withdrawal of calcium salts from the bony system associated with pulmonary tuberculosis might, according to Miller, ${ }^{24}$ cause a horizontal wasting of the alveolar process. This theory of demineralization of bone in cases of pulmonary tuberculosis seems to be unfounded. ${ }^{36}$
\end{abstract}

A second group of investigators have found, in tuberculous patients, an increased occurrence and extent of the commonly recognized types of periodontal diseases. ${ }^{13,32}$ These reports include a large number of clinical cases and a significant relationship is claimed between pulmonary tuberculosis and periodontal disease, utilizing healthy individuals as controls. In several textbooks of oral pathology ${ }^{1,7,}{ }^{20}$ general statements are made about pulmonary tuberculosis causing lowered systemic and local resistance to irritation and infection, and thereby predisposing to periodontal disease.

The third group of reports is headed by Tanchester and Sorrin's thorough investigation of 1,500 tuberculous patients plus a large number of healthy controls. They did not find any pathognomonic dental or periodontal signs of tuberculosis, nor did they observe more dental or periodontal disease in tuberculous than in healthy individuals. Roentgenographic examination of the teeth and their supporting structures did not reveal any changes which could be attributed to tuberculosis. Similar statements have been made by Brodsky, ${ }^{4}$ Ordene, ${ }^{27}$ and Gruber ${ }^{18}$ after examination of a large number of tuberculous patients.

Received for publication, June 1, 1951

From a thesis submitted for the degree of Ph.D. at the University of Michigan. 
Most of the reports are based on clinical impressions rather than on scientifically controlled investigations, making an evaluation of the literature impossible. The etiology of periodontal disease is considered by many investigators to be obscure, local factors are often difficult to observe, and systemic disease, when present, offers a seemingly plausible explanation of the periodontal involvement. This "systemic factor escape" in the diagnosis of periodontal disease is a vague concept which has been indiscriminately used and which has impaired the progress in dentistry tremendously.

\section{INVESTIGATION}

Clinical examination followed by necropsy and histologic study was performed in 10 rhesus monkeys which suffered from severe tuberculosis of the human type. Seven healthy monkeys of approximately the same age which lived under the same environmental conditions. were used as controls. The tuberculous animals were sacrificed when they reached the moribund stage of their disease. Clinical oral and grossly visible visceral changes were recorded, oral photographs and dental roentgenograms were taken, and models were made of their teeth. Specimens for microscopic study were taken from jaws, teeth, temporomandibular joints, mesial end of one tibia, and from visceral organs, including the lung, peribronchial and mesenteric lymph nodes, stomach, liver, kidney, spleen, adrenals, and pancreas. Hematoxylin and eosin stained sections were utilized for examination of all of the tissues. The seven control animals were sacrificed and examined in the same way as the experimental animals.

A summary of the case reports is given in Table I. Nine of the monkeys had, at the time of autopsy, extensive miliary spread of pulmonary tuberculosis with lesions in spleen, liver, kidney, pancreas, and peribronchial and mesenteric lymph nodes. The tenth monkey had severe renal tuberculosis. They all showed evidence of catarrhal gastritis and colitis, and a few animal parasites were found in 3 of the monkeys. Four of the experimental animals had clinically normal gingiva, while the other 6 showed varying degrees of materia alba, dental calculus, and a mild marginal gingivitis of the same type as seen in the control animals. The gingivitis was seen only in association with local irritants. The dental roentgenograms did not reveal any bone changes and microscopically no difference could be observed between the periodontal tissues in the experimental and the control animals. Various manifestations of traumatism, in some instances histologically resembling diffuse atrophy or periodontosis, ${ }^{26}$ were present in both groups. The implications of these findings have been discussed in a previous article. ${ }^{29}$

Since degeneration of periodontal fibers has been listed as the initial and most important finding in periodontosis,, ${ }^{3,15,17}$ it was felt that a logical approach to the problem of possible periodontal impairment in systemic disease (here tuberculosis) would be a thorough investigation of the collagen for general changes, for example in joint capsules and for changes localized in the periodontal tissues. The collagenous fibers are a characteristic constituent of 
all types of connective tissue, and there is no more important group of substances in dental physiology and pathology than the collagen group of fibroproteins. $^{11}$

In the loose connective tissue the collagenous fibers are long, straight or wavy, colorless threads or ribbons which run in all directions. ${ }^{23}$ In connective tissue, which performs a definite function, they are arranged parallel in such a way as to allow the function to be transferred as a pull to the collagenous fibers. They consist of extremely fine, uniform, parallel, collagenous fibrils which are held together by a cement substance. The fibers are very flexible, but not elastic, and offer a great resistance to a pulling force.

A satisfactory definition of collagen has not been devised. Morphologists have gained a common concept of the meaning of the term through descriptive terminology and regard collagen as a homogenous, fibrillary, intercellular protein substance which can be distinguished from other intercellular materials by its staining reactions, microscopic structure, and other empirical properties. The source of collagen has not been proved definitely. It appears in the

TABLE I

MONKEYS WiTH Tuberculosis**

\begin{tabular}{|c|c|c|c|c|}
\hline $\begin{array}{l}\text { MONKEY } \\
\text { NUMBER }\end{array}$ & $\begin{array}{c}\text { AGE } \\
\text { YEARS }\end{array}$ & $\begin{array}{l}\text { CLINICAL PERIODON'TAI } \\
\text { DIAGNOSIS }\end{array}$ & $\mid \begin{array}{c}\text { MATERIA ALBA } \\
\text { AND/OR } \\
\text { CALCUILS }\end{array}$ & $\begin{array}{c}\text { MICROSCOPIC PERIODONTAL } \\
\text { DIAGNOSIS }\end{array}$ \\
\hline 1514 & $31 / 2$ & $\begin{array}{l}\text { Mild gingivitis } \\
\text { Stillman's eleft }\end{array}$ & + & Mild ehronic gingivitis \\
\hline 1775 & 3 & Normal gingiva & - & Normal gingiva \\
\hline 1641 & 4 & Normal gingiva & - & Mild chronic gingivitis \\
\hline 1643 & $31 / 2$ & Mild gingivitis & + & Mild chronie gingivitis \\
\hline 1950 & $21 / 2$ & Mild gingivitis & + & Chronic gingivitis \\
\hline 1328 & $4-5$ & Normal gingiva & - & Mild chronic gingivitis \\
\hline 1921 & 2 & Normal gingiva & - & Mild chronic gingivitis \\
\hline 1842 & 2 & Mild gingivitis & + & Gingivitis \\
\hline I & 2 & Gingivitis & + & Chronie gingivitis \\
\hline 1771 & $5-6$ & Mild gingivitis & + & Mild chronic gingivitis \\
\hline
\end{tabular}

* The dental roentgenograms were negative. All
signs of gingivitis, both clinically and microscopically.

intercellular medium only in the presence of fibroblasts, and Hass and McDonald ${ }^{19}$ showed in tissue cultures that new deposits of collagen appeared only in the immediate vicinity of a new growth of fibroblasts. ${ }^{38}$ It was also found that new collagen did not appear in increasing quantities or persist for a significant interval of time around fibroblasts which showed morphological evidence of diminished viability. The first detectable stage in the process of resorption of collagen was a loss of the selective staining property. One could assume that the same phenomena would initiate periodontosis. A depression of the $\mathrm{pH}$ level of the medium to the lowest level which permitted the fibroblasts to live was associated with cessation of collagen deposition and resorption of collagen. The low $\mathrm{pH}$ level in an area of inflammation may also partly explain the collagen degeneration found in association with inflammation.

Pathologic changes in collagen are manifest as degenerative changes, and result from many causes, which include allergy, disturbance in metabolism, toxic influences, drugs, foreign proteins, endocrine imbalances, aging, and 
reaction to excessive stress and inflammation. In addition, so-called collagen diseases exist, including serum sickness and scleroderma. The products of degeneration of collagen may be distinguished by staining reactions. The collagen first ceases to stain with acid dyes and stains with basic dyes. The structure of normal collagen is retained in this early stage of degeneration. Degenerative changes begin in the center of the fiber. ${ }^{22}$ As the degenerative changes proceed, acid-staining collestin is formed. The collagen disintegrates into coarse, irregular masses or blocks. A more advanced degenerative produet of collagen is the intensely basophilic-staining collacin. Atrophy and destruction of the collagenous fibers also occur in the chronic infective granulomatous processes such as tuberculosis and syphilis.

Little research has been reported with reference to collagen in periodontal tissues. Stafne and Austin $^{34}$ reported widened periodontal spaces in $x$-ray films of patients with acroselerosis and diffuse scleroderma. They found that the enlarged periodontal space was filled with loose vascular connective tissue. Ray ${ }^{30}$ reported collagen degeneration in some gingival specimens from diabeties. The change in collagen was associated with inflammation, which made it difficult to evaluate the significance of the findings. Orban, Martin, and Helm, ${ }^{2 \overline{5}}$ in a case of scorbutus, demonstrated an increase in the formation of collagenous fibers in the gingiva when the scurvy improved.

In the reported cases of diffuse atrophy of the periodontal tissues, hematoxylin-eosin stains and in a few cases, silver stains, have been used to study collagen change. Collagenous degeneration has been diagnosed by the finding of dearrangement of the fibers rather than by staining reactions. Fixation of tissues from the jaws is often delayed in autopsy material. Uneven, inadequate fixation may also result from poor penetration of the fixative into these dense tissues. One portion of a specimen may be fixed and show cell details, while another portion of the same jaw may be inadequately fixed and the artefact which results might be misinterpreted as degenerative change. Material containing teeth requires a longer period of decalcification than ordinary bone, and sections including teeth are often uneven in thickness. The above technical factors are emphasized because they are important in the evaluation of collagen stains of jaw sections.

Various techniques for silver stains were tried. The best results were obtained with Rio Hortega's triple impregnation, but the silver stains were all uncertain in their action on decalcified and celloidin-embedded material ${ }^{16}$ and no reliable color reaction indicating collagen degeneration could be established.

Heidenhain's modification of Mallory's connective tissue stain seemed more dependable and was utilized for a large number of sections both from jaws and joints, ineluding experimental and control animals. Even with this method it proved to be very difficult to differentiate between slight degree of artefact and early collagen degeneration, so at least 10 to 15 sections from each specimen should be stained and compared before an interpretation of details is attempted. These technical hazards are discussed because they offer some explanation of the wide range of different findings and opinions en- 
countered in the literature, although the main source of error in histological reports on periodontosis and systemic disease has been the lack of acceptable control material.

This investigation of the collagen fibers did not show any difference between the experimental and the control animals, neither in sections from joints nor in sections from jaws and teeth. The main variable factor, with reference to periodontal disease, which is present in man and absent in monkeys, is variations in the personal oral hygiene. The literature generally points out that the oral hygiene is poor in patients with far-advanced tuberculosis. ${ }^{12,35}$ If tuberculous human beings have a higher incidence of and a more severe periodontal disease than healthy individuals, it is probably on the basis of impaired oral hygiene rather than a change in the resistance of the periodontal tissues.

\section{SUMMARY}

1. No periodontal changes were observed that could be attributed to tubereulosis in 10 rhesus monkeys.

2. No indication of collagen changes was noted in sections from jaws and joints.

3. No observations substantiated the theory of lowered periodontal resistance in tuberculosis.

4. Any increase in incidence of periodontal disease associated with tuberculosis must be produced by local factors of which poor oral hygiene appears to be the most significant.

5. Traumatic periodontal changes resembling diffuse atrophy or periodontosis were observed both in the experimental and in the control animals.

\section{REFERENCES}

1. Appleton, J. L. T., Jr.: Bacterial Infection, Pbiladelphia, 1933, Lea and Febiger.

2. Belding, L. J., and Belding, P. H.: An Evaluation of the Various Theories on the Etiology of Periodontoclasia, D. Cosmos 75: 140, 1933.

3. Boyle, P. E., Bessey, O., and Wolbach, S. B.: Fixperimental Production of the Diffuse Alveolar Bone Atrophy Type of Periodontal Disease by Diets Deficient in Ascorbic Acid (Vit. C), J.A.D.A. 24: 1768, 1937.

4. Brodsky, R. H.: Tuberculosis of the Mouth, Ann. Dent. 6: 167, 1947.

5. Brody, H.: Influence of Pulmonary Tuberculosis on the Diseases of the Mouth, $D$. Cosmos 64: 407, 1922.

6. Bryan, A. W.: Progress in the Recognition of the Etiologic Factors in Periodontal Disease, $J$. Periodont. 10: 25, 1939.

7. Burket, L. W.: Oral Medicine. Philadelphia, 1946, Lippincott Co.

8. Cahn, L. R.: Observations on the Effect of Tuberculosis on the Teeth, Gums and Jaws, D. Cosmos 67: 479, 1925 .

9. Cipes, B. J.: Oral Hygiene in Relation to Tuberculosis, D. Cosmos 68: 50, 1926.

10. Citron, J.: Zur Frage der internistischen Aetiologie der Paradentose, Zahnarzt. Rund. 37: No. 32, 1928.

11. Fish, W. E.: Surgieal Pathology of the Mouth, London, 1948, Sir Isaac Pitman and Sons.

12. Franke, J.: Dystrophische Paradental Disposition, Deutsche Zahnarzt. Zeit. 3: 505, 1948.

13. Gardner, W. M.: Teeth of the Tuberculous, J. Outdoor Life 23: 77, 1926.

14. Goadby, K.: Diseases of the Gums and Oral Mucous Membrane, ed. 4, London, 1931, Oxford University Press.

15. Goldman, H. M.: Periodontosis in the Spider Monkey, J. Periodont. 18: 34, 1947.

16. Gomori, G.: Effect of Certain Factors on Results of Silver Impregnation of Reticulum Fibers, Am. J. Path. 15: 493, 1939.

17. Gottlieb, B.: Zur Aetiologie und Therapie der Alveolarpyorrhoe, Ztschr. Stomatol. 18: 59,1920 . 
18. Gruber, I. E.: The Condition of the Teeth and the Attachment Apparatus in Tuberculosis, J. D. Res. 28: 483, 1949.

19. Hass, G., and MeDonald, F.: Studies of Collagen. I and II, Am. J. 'Path. 16: 525, 1940.

20. Hill, T. J.: Oral Pathology, ed. 4, Philadelphia, 1949, Lea and Febiger.

21. Kramer, C. S.: Osseous Trophie Changes in the Jaws and Palate in the Tuberculous, J. A. D. A. 12: 1117, 1925 .

22. Mcleod, J. M. H., and Muende, I.: Pathology of the Skin. New York, 1946, Paul B. Hoeber.

23. Maximow, A.: Development of Argyrophile and Collagenous Fibers in Tissue Cultures, Proc. Soc. Exper. Biol. \& Med. 25: 439, 1928.

24. Miller, S. C.: Textbook of Periodontia, ed. 2, Philadelphia, 1947, The Blakiston Co.

25. Orban, B., Martin, W. B., and Helm, R. M.: Histopathologie Investigation of a Case of Seorbutic Gingivitis, J. Periodont. 18: 95, 1947.

26. Orban, B., and Weinmann, J. P.: Diffuse Atrophy of the Alveolar Bone (Periodontosis), J. Periodont. 13: 31, 1942.

27. Ordene, N. M.: Dental Aspects of Tuberculosis, N. Y. State D. J. 14: 300, 1948.

28. Parma, C.: Histopathology of Periodontosis, J. D. Res. 27: 766, 1948.

29. Ramfjord, S.: Effects of Acute Febrile Diseases on the Periodontium of Rhesus Monkeys With Reference to Poliomyelitis, J.D. Res. 30: 615, 1951.

30. Ray, H. G.: A Study of the Histopathology of the Gingiva in Patients With Diabetes Mellitus, $J$. Periodont. 19: 128, 1948.

31. Rhein, M. L.: Etiological Classification of Pyorrhea Alveolaris, D. Cosmos 36: 779, 1894.

32. Roddy, J. A., Funk, E. H., and Kramer, D. W.: Pyorrhea Alveolaris, N. Y. Med. J. 104: $433,1916$.

33. Schmuziger, P.: Primare Mundschleimhaut Tuberculose, Schw. Monat. f. Zahn. 55: 1087, 1945.

34. Stafne, E., and Austin, L.: A Characteristic Dental Finding in Acroselerosis and Diffuse Scleroderma, $J$. Orthodontics $30: 25,1944$.

35. Tanchester, D., and Sorrin, S.: Dental Lesions in Relation to Pulmonary Tuberculosis, J. D. Res. 16: 69, 1937.

36. Weinmann, J. P., and Sicher, H. D.: Bone and Bones, St. Louis, 19 1 , The C. V. Mosby Co.

37. Wissler, H.: Die Primare Mundschleimhaut-Tuberculose, Schw. Monat. f. Zahn. 54: 905, 1944.

38. Wolbach, S. B.: Controlled Formation of Collagen and Reticulum. A Study of the Source of Intercellular Substance in Recovery From Experimental Scorbutus, Am.J.Path. 9: 689, 1933. 